\title{
Reflections on How to Better Communicate Political Science's Public Value
}

\section{Citation}

Hochschild, Jennifer. 2015. "Reflections on How to Better Communicate Political Science's Public Value." APSC 48 (S1) (August 4): 115-117. doi:10.1017/s1049096515000530.

\section{Published Version}

doi:10.1017/S1049096515000530

\section{Permanent link}

http://nrs.harvard.edu/urn-3:HUL.InstRepos:30403701

\section{Terms of Use}

This article was downloaded from Harvard University's DASH repository, and is made available under the terms and conditions applicable to Open Access Policy Articles, as set forth at http:// nrs.harvard.edu/urn-3:HUL.InstRepos:dash.current.terms-of-use\#OAP

\section{Share Your Story}

The Harvard community has made this article openly available.

Please share how this access benefits you. Submit a story.

\section{Accessibility}


<section header>Section III: NEW OPPORTUNITIES

<running head>Section III: REFLECTIONS ON POLITICAL SCIENCE'S PUBLIC VALUE

$<$ title>REFLECTIONS

<author>Jennifer Hochschild, Harvard University

In John Aldrich and Arthur Lupia, eds. Let's Be Heard: How to Better Communicate Political

Science's Public Value.

In PS: Political Science \& Politics, 2015.

$<5$-line drop cap initial text $><$ start text $>$ t take my cue for these comments from a clause in the Introduction: the goal of the task force is to identify "means by which individual scholars and professional organizations can make political science's insights and discoveries more accessible, more relevant, and more valuable to more people." I separately consider each desirable characteristic, although, of course, they are tightly linked in practice and perhaps conceptually. This article focuses on tensions and complexities - not because I think the task force mission is unworthy or impossible but rather because it is so worthy that we must do everything possible to enable its success. That involves looking at issues as well as goals and strategies.

$<$ text>Relevant: This is a fighting word within political science, as it probably is in other disciplines. Opposition to relevance can emerge from fusty academicism (in the negative sense), a strong sense of entitlement for scholarship in general or my own research program in particular, or a form of elitism that assumes the public's unwillingness or inability to understand our complex endeavors. Indeed, political scientists can be surprisingly scornful of practicing politicians (unlike, e.g., economists who tend not to scorn successful corporate leaders). 
However, there are other more justifiable reasons to be wary of the demand for relevance. Political philosophers or scholars of the history of ideas seldom can expect political actors or the general public to care much about their research. Since a distinctive feature of political science compared with other social sciences is the importance of a deep and robust philosophical and historical tradition, we must be careful not to allow the implication that philosophical or historical scholarship is somehow less valuable to the American Political Science Association (APSA) because it is less directly relevant to public actors and most citizens. ${ }^{1}$ From the other end of the epistemological spectrum, many political scientists engage in highly technical research that focuses on carefully specified questions of causal inference, possible implications of particular institutional designs, or unforeseen trajectories of particular decision-making processes. Their work also is difficult to make relevant to political actors and most citizens, in part because the need for precision to take advantage of sophisticated techniques often entails a narrow substantive focus or abstruse mathematics.

The call for relevant political science points to a deeper conundrum that has long puzzled me. Research on causes, processes, and institutions tends to have much higher status in our discipline than research on policy content, implementation practices, and outcomes. (As a colleague once told me, "Scholars study causes; journalists look at outcomes.") To state it more categorically, many political scientists seek to abstract away from real-world problems, politicians' actions, or policy dilemmas on the grounds that such things are idiosyncratic, contingent, or otherwise inelegant. In fact, this may be true much of the time-such is life. But the push for relevance sits uneasily beside the desire for theoretical parsimony, the search for 
law-like regularities, or the valorization of "deeper" causes that are manifested in, for example, judgments about what to publish in the highest status disciplinary journals.

This generalization, like all of those in this set of reflections, has important exceptions. Nevertheless, the call for relevance specified in the Introduction and implicit in the task force mission as a whole evokes mixed reactions in me and will, I expect, be even more controversial in the discipline as a whole. On the one hand, the APSA and its members must be careful not to marginalize the types of political science that do not fit well into a framework of public relevance. On the other hand, I (for one) would be delighted to see more engagement with and respect for political science research that attends to substantive policy issues, outcomes of legislative processes, implementation of enactments, politicians' tactics, and other phenomena directly relevant to public actors. Thus the task force report needs to tread a fine line: showing how to use technology and training to enhance the visibility and impact of publicly relevant research without undermining respect for research with minimal or at least non-obvious public relevance.

Accessible: Here as well, I am all in favor of the goal, but it also raises issues that warrant consideration. The articles and Introduction discuss important difficulties in enhancing access: increasing public connections with political scientists' research is expensive, time-consuming, and difficult to do well. Appropriate strategies and tactics are not always clear, technology can fail in embarrassingly visible ways, the effort may not be rewarded at promotion and tenure, and organizations such as the APSA, departments, and universities are deeply conservative in their structures and behaviors. Moreover, the competition for the attention of the public and 
political officials is fierce and unrelenting. Nevertheless, task force members have developed elegant, persuasive ideas for promoting public access to our work.

My observation here builds from a paraphrase of a famous statement by Max Planck: "Science advances one funeral at a time." That is, those scholars with the greatest ability and strongest incentive to develop and implement new technologies to make political science research accessible to public officials and a wider community tend to be younger, whereas those who control the resources, institutions, and gateways in which they work tend to be older. (To avoid crude age-grading, "younger" and "older" can be understood as professionally less and more experienced.) Again, we must be wary of overgeneralizing-but it is striking how many task force members are in the early and middle stages of their career. It is not surprising that so many link the task force agenda to the issues typically most salient to scholars at those stages: how to obtain tenure and promotion, have an impact on peers within the discipline, promote new fields of scholarship and new methods or frameworks of analysis, and get published. As a result, for many task force members, developing a public presence is closely linked with desired reforms in the practice of political science, the activities of the APSA, and career prospects.

The generational implications of a serious effort to promote public access suggest a shift in power dynamics within the political science profession. It seems plausible that scholars who are professionally young enough to be comfortable with technological innovation, but old enough to be past the tenure hurdle, will be implementing the new strategies for access. The more substantial the resources that the APSA puts into accessibility in the public arena, the 
more we can foresee mixed reactions among those either too junior to feel comfortable taking risks to promote public accessibility or too senior to feel comfortable with this new priority.

These mixed reactions may be exacerbated by the tradeoffs that are likely to accompany a strong emphasis on promoting public access. Many of the attractive new technologies and practices-an APSA-sponsored e-journal; support for blogging; video and other electronic enhancements at conferences; training in public communication; reallocation of APSA staff time; hiring a communications director or webmaster; and, above all, open access to journal articles-are expensive as well as intentionally disruptive of old technologies and practices. The association, like the rest of us, typically seeks to add new activities and goals without eliminating older ones; however, at some point, that becomes unsustainable. So, what will have to give way? Dues can be raised but possibly at the cost of losing some members. Conference panels can be made much stronger but possibly at the cost of reducing participation. An e-journal may serve the interests of some types of research or publication more than others. It is surely an exaggeration to assert that "a comprehensive OA [open access] paradigm is pretty much a frontal assault on professional societies" ${ }^{2}$ - but open access does pose challenges as well as offering wonderful benefits. Just as relevance unintentionally gives precedence to some types of research, so does accessibility unintentionally give precedence to scholars at some career stages and allocates scarce resources to some goals over others. $<$ Insert PQ1 about here> Valuable: Again, I endorse the idea of making political scientists' research more valuable to public officials and the general public, and task force members' ideas are ingenious and persuasive. Many suggestions not already subsumed by the concepts of relevance and 
accessibility focus on enhancing the quality of scholarship per se-for example, accelerating the review process and making it fairer, mitigating publication bias, and promoting replication. Others focus on expanding our audience to include political scientists outside of academia, journalists, the interested lay public, policy makers, libraries and museums, and teachers. The ideas seem exciting and constructive.

People have long struggled to understand why scholars in general and political scientists in particular find it so difficult to connect with those outside of the field. The answer is not that political scientists are especially abstruse or verbally inept compared with scholars in other disciplines. Instead, comparing economists and psychologists, on the one hand, to sociologists and anthropologists, on the other hand, can be illuminating. The former two professions have public visibility and prestige-through the Council of Economic Advisors, the Federal Reserve Bank, the employment of economists in corporations and governments at all levels, the Nobel Prize in Economics, and the ubiquity of clinical psychologists. There are no equivalent public or private positions for sociologists, anthropologists_or political scientists. In fact, practicing politicians often disdain or even fear political science (e.g., witness the 2013 ban on National Science Foundation [NSF] funding of most political science research). ${ }^{3}$ Similarly, few national or international data-collection efforts include political variables analogous to the material generated by the Bureau of Labor Statistics and The World Bank.

Thus, the effort to make our research valuable to people outside of the academy points to a third basic tension. This tension lies not within political science but between us and the world: we are committed to a discipline that relatively few outsiders find useful-at least as evidenced institutionally-and that some find threatening. Again, there are important 
exceptions; political scientists have helped to write constitutions, develop electoral systems, and improve the quality of political campaigns. However, we lack the type of highly visible or professionally remunerative external validation that leads public officials or the general public to almost reflexively grant legitimacy to our work.

How well political scientists can overcome our relative invisibility and impotence in the public arena remains to be seen - although the energy and good ideas of this task force can make a difference. How much we actually want to fight that lack of direct impact is perhaps a more difficult and interesting question. Here the complexity of relevance returns, in a different way from that already discussed. Do political scientists risk losing their status as objective scholars if their work becomes highly valuable to, for example, one political candidate or party? Should the research of political scientists whose avowed purpose is empowerment of a disadvantaged group - or protection of powerful banks and corporations - be evaluated differently from the research of those who aspire to neutral science? Is an excellent community college teacher just as valuable to the public, or more so, as an author of an article in the highest ranking disciplinary journals? Is a field experiment that turns out to affect the outcome of an election ethically harmful rather than valuable, despite being highly relevant?

These questions are framed rhetorically, but their answers, if taken seriously, could shape the direction of much scholarly inquiry, the balance between teaching and research, and ethical guidelines for our professional activities. What it means for political science to become "more valuable to more people" without also losing value warrants careful consideration. <Comp: insert PQ2 about here> 
In summary, the APSA task force on Improving Public Perceptions of Political Science's

Value has taken on an even larger set of tasks than its members realized. If fully implemented, the proposals will subtly shift the relative value of research types within the discipline, change the relative influence of people at different career stages, reallocate APSA resources, promote new forms of institutional engagement with the discipline, and perhaps change our standards for what counts as appropriate research. All of these structural changes may well be worthwhile, but they will not be costless or easy to accomplish.<end slug> <PULL QUOTES> $<$ PQ1 > Just as relevance unintentionally gives precedence to some types of research, so does accessibility unintentionally give precedence to scholars at some career stages and allocates scarce resources to some goals over others.

<PQ2> Thus, the effort to make our research valuable to people outside of the academy points to a third basic tension: we are committed to a discipline that relatively few outsiders find useful-at least as evidenced institutionally-and that some find threatening.

$<$ header $>$ NOTES

$<e n>^{1} \mathrm{Few}$ if any members of the task force are philosophers or historians of ideas, and most examples in the articles taken from other disciplines focus on the sciences or the more scientifically oriented social sciences. It would be illuminating to examine what, for example, the MLA and American Historical Association are doing to foster public engagement with and appreciation for the humanities.

${ }^{2}$ See http://scholarlykitchen.sspnet.org/2013/08/01/open-access-and-professional-societies.

${ }^{3}$ In March 2013, "although his original intention to abolish NSF's $\$ 10$ million political science funding and redistribute $\$ 7$ million of it to the National Cancer Institute did not succeed, [Senator Tom] Coburn managed to have the Democratic leadership accept a 'modified' version of the amendment that restricts the projects the political science program can fund. The new version allows NSF funding for political science projects only if the Foundation's Director certifies in writing that the project is 'promoting national security or the economic interests of the United States.' ... This appeared to satisfy the Senator from Oklahoma who has criticized studies of 
Congress and voting behavior for years. . . The amendment passed. Not one Senator spoke against it or defended political science or NSF's merit review process for selecting grants. Sen. Carl Levin (D-MI) issued a statement deploring Coburn's amendment the day after." See www.apa.org/science/about/psa/2013/04/political-sciencefunding.aspx. 